\title{
Uncertainty in Estimation of Anthropogenic Aerosol Indirect Effect
}

\author{
Xiangjun Shi \\ Hebei Climate Center \\ Hebei Meteorological Bureau \\ Shijiangzhuang, China \\ e-mail: xiangjun.10@gmail.com
}

\author{
Xiefei Zhi \\ Nanjing University of Information Science and Technology \\ Nanjing, China \\ e-mail: zhi@nuist.edu.cn
}

\begin{abstract}
In this paper, uncertainties in estimating anthropogenic aerosol indirect effects on warm clouds are explored using the recently developed Grid point Atmospheric Model (GAMIL) with prescribed aerosol fields. The anthropogenic aerosol indirect effect is calculated by the change in shortwave cloud forcing from preindustrial times to present-day. Simulations show anthropogenic aerosol indirect effect is not sensitive to two different physically-based droplet nucleation parameterizations. However, anthropogenic aerosol indirect effect is quite sensitive to the assumption on the subgrid vertical velocities, which are used to drive physicallybased droplet nucleation parameterization. Furthermore, sensitivity simulations indicate that aerosol influence on convective clouds, which is not considered in GAMIL model, might be an important contributor to anthropogenic aerosol indirect effect.
\end{abstract} change

Keywords-aerosol indirect effect; uncertainty; climate

\section{INTRODUCTION}

Aerosol particles could modify the optical properties of warm clouds through the so-called aerosol indirect effect in which aerosol particles act as cloud condensation nuclei $(\mathrm{CCN})$, thereby changing the cloud microphysical properties and hence radiative transfer [1,2]. Although the aerosol indirect effect has been studied extensively in the recent decades, it is still associated with a low level of understanding due to the complexity of the aerosol-cloud interaction, as well as the wide range of scale on which these interactions occur. In this paper, we investigate the uncertainty of anthropogenic aerosol indirect effect on warm clouds.

Linking aerosol particles to cloud droplet formation is the root of aerosol influence on warm clouds. In recent years, physically-based parameterizations have been widely used in global models. Here we firstly investigate the sensitivity of anthropogenic aerosol indirect effect to two different physically-based droplet nucleation parameterizations. Representation of clouds remains a big challenge in GCMs $[3,4]$. Some simplifications must be made due to the vast range of temporal and spatial scales in cloud processes [5]. The influences of these simplifications on aerosol indirect effect are also evaluated in this paper.

\section{Model Description}

The global atmospheric modeling tool in this study is the new version of Grid-point Atmospheric Model of IAP LASG (GAMIL). Compared to default GAMIL, the new developed GAMIL could represent aerosol indirect effect in a much more realistic manner [6]. In two-moment bulk stratiform cloud microphysics scheme scheme, droplet nucleation process is represented by the physically-based parameterization of Abdul-Razzak and Ghan (hereafter AG). Besides of this parameterization, another physically-based droplet nucleation parameterization developed by Nenes and Seinfeld (hereafter NS) has also been included [7, 8]. A subgrid vertical velocity $\left(W_{\text {sub }}\right)$ that incorporate the effect of subgrid variability of vertical velocity on calculating droplet nucleation is provided. A lower limit of $0.1 \mathrm{~m} \mathrm{~s}^{-1}$ is assumed for weak turbulent diffusion. Prescribed aerosol data recommended by the Coupled Model Intercomparison Project (CMIP5) are used for droplet nucleation parameterization. The convective cloud processes are presented by the modified Zhang-McFarlane convective cloud scheme. The conversion of cloud water to rain is represented by a given coefficient $C_{0}\left(0.5 \times 10^{-3} \mathrm{~m}^{-1}\right.$ in GAMIL). The detrained cloud water is added to stratiform cloud. Number concentrations of convective detrainment are calculated by assuming a mean radiusof $16 \mu \mathrm{m}$ and $32 \mu \mathrm{m}$ for droplets $\left(R_{d}\right)$ and ice crystals, respectively.

\section{Different Physically-Based Droplet Nucleation PARAMETERIZATIONSU}

All simulations in this paper were carried out in approximate $2.8^{\circ} \times 2.8^{\circ}$ horizontal resolution and 26 vertical levels with a time step of $20 \mathrm{~min}$, using climatological sea surface temperature. Each simulation was run for 5 years after an initial spin-up of 4 months. Anthropogenic aerosol indirect effects from two different physically-based droplet nucleation parameterizations (AG and NS, Table I) are examined here. Each experiment included two simulations, present-day (PD) simulation forced by annually-cyclic aerosol data for the 1990s and preindustrial (PI) simulation forced by aerosol data for the 1870s. 
TABLE I. Descritpion of All EXPERIMENTS In This PAPER.

\begin{tabular}{|l|c|}
\hline \multicolumn{1}{|c|}{ Experiments } & Description \\
\hline $\mathrm{AG}$ & $\mathrm{AG}, C_{0}=0.5^{*} 10^{-3} \mathrm{~m}^{-1}, R_{d}=16 \mu \mathrm{m}, W_{\text {sub }}>0.1 \mathrm{~m} \mathrm{~s}^{-1}$. \\
\hline $\mathrm{BN}$ & same as AG, but using BN parameterization. \\
\hline $\mathrm{W}_{\text {sub }}$ & same as AG, but $W_{\text {sub }}>0.3 \mathrm{~m} \mathrm{~s}^{-1}$. \\
\hline $\mathrm{C}_{0}$ & same as AG, but $C_{0}=3.0^{*} 10^{-3} \mathrm{~m}^{-1}$. \\
\hline $\mathrm{R}_{\mathrm{d}}$ & same as AG, but $R_{d}=8 \mu \mathrm{m}$, only for PI condition. \\
\hline
\end{tabular}

An overview of various global annual mean diagnostics is provided in Table II. Global mean column cloud droplet number concentrations with NS parameterization are larger than AG for both PD and PI conditions. This result is consistent with the tendency of NS parameterization to diagnose higher $\mathrm{CCN}$ than $\mathrm{AG}$ parameterization for most conditions [9]. Because of cloud lifetime effect, simulations with NS parameterization also produce larger liquid water path than AG simulations. Consequently, global annual mean short wave cloud forcing (SWCF) with NS parameterization are higher than $\mathrm{AG}$ parameterization, -1.4 $\mathrm{W} \mathrm{m} \mathrm{m}^{-2}$ for PD condition and $-1.5 \mathrm{~W} \mathrm{~m}^{-2}$ for PI condition. The anthropogenic aerosol indirect effect defined as the global mean difference in SWCF between PD and PI amounts -1.4 $\mathrm{W} \mathrm{m}{ }^{-2}$ with $\mathrm{AG}$ parameterization and $-1.3 \mathrm{~W} \mathrm{~m}^{-2}$ with $\mathrm{NS}$ parameterization. The difference is remarkably small. This indicates that anthropogenic aerosol indirect effect is not sensitive to physically-based droplet nucleation parameterizations.

Table II. Global Mean Cloud Properties From Various Simulations For PD (suffix PD) ANd PI Condition (PostFix PI).

\begin{tabular}{|c|c|c|c|}
\hline Experiments & $\operatorname{SWCF}\left(\mathrm{W} \mathrm{m}^{-2}\right)$ & LWP $\left(\mathrm{g} \mathrm{m}^{-2}\right)$ & CDNUMC $\left(10^{10} \mathrm{~m}^{-2}\right)$ \\
\hline $\mathrm{AG}_{\mathrm{PD}}$ & -53.9 & 61.6 & 1.70 \\
\hline $\mathrm{AG}_{\mathrm{PD}}$ & -52.5 & 59.0 & 1.49 \\
\hline $\mathrm{NS}_{\mathrm{PD}}$ & -55.3 & 63.4 & 1.76 \\
\hline $\mathrm{NS}_{\mathrm{PI}}$ & -54.0 & 60.4 & 1.55 \\
\hline $\mathrm{W}_{\text {subPD }}$ & -56.4 & 69.1 & 2.18 \\
\hline $\mathrm{W}_{\text {subPI }}$ & -54.2 & 62.4 & 1.66 \\
\hline $\mathrm{C}_{\mathrm{OPD}}$ & -50.0 & 54.4 & 1.58 \\
\hline $\mathrm{C}_{\mathrm{OPD}}$ & -48.3 & 51.4 & 1.33 \\
\hline $\mathrm{R}_{\mathrm{dPI}}$ & -54.6 & 74.7 & 2.10 \\
\hline
\end{tabular}

IV. UnCertainties in Cloud SCheme

Global models with their grid spacing of the order of 100 $\mathrm{km}$ are unable to resolve cloud scale vertical motions. Thus, global models provide only one characteristic updraft velocity that denotes the influence of sub-grid variability of vertical velocity on droplet nucleation. In this method, a minimum of updraft velocity is usually assumed, and this minimum value is treated as a tuning parameter because it is difficulty to constrain the sub-grid variability with current observations [10]. In GAMIL, the minimum value is set to $0.1 \mathrm{~m} \mathrm{~s}^{-1}$ following [5]. It is lower than other study $\left(0.3 \mathrm{~m} \mathrm{~s}^{-1}\right.$ in [11]). In order to evaluate the impact of this lower limit on aerosol indirect effect, we set up a sensitivity experiment ( $\mathrm{W}_{\text {sub }}$, Table $\left.\mathrm{I}\right)$, in which the minimum value was increased to $0.3 \mathrm{~m} \mathrm{~s}^{-1}$. Because activated aerosol number fraction strongly depends on updraft velocity, global mean column cloud droplet number concentrations from $\mathrm{W}_{\text {sub }}$ experiment are remarkably larger than AG experiment, especially for PD condition (Table II). As a result, anthropogenic aerosol indirect effect from $\mathrm{W}_{\text {sub }}$ is increased to $-2.2 \mathrm{~W} \mathrm{~m}^{-2}$, which is remarkable larger than $\mathrm{AG}\left(-1.4 \mathrm{~W} \mathrm{~m}^{-2}\right)$.

The aerosol influence on convective clouds is not included in the current estimations of aerosol indirect effect because it is very difficulty for GCMs to explicitly parameterize this indirect effect [9]. In Zhang-McFarlane convective cloud scheme, the conversion of suspended liquid water droplets to rain is described by a tunable parameter $C_{0}$ $\left(2.0 \times 10^{-3} \mathrm{~m}^{-1},[12]\right)$. Actually, $C_{0}$ denotes several individually microphysical processes that strongly depend on droplet number concentration. So that $C_{0}$ should be relevant to aerosols. Besides, the droplets radius of convective detrainment $\left(R_{d}\right)$, which is a tunable parameter, should also be relevant to aerosols. Here, we try to figure out if the impact of aerosols on convective clouds is an important component for simulating aerosol indirect effect. To do so, two sensitivity experiments (Table I) are constructed by changing these above two tunable parameters, $C_{0}$ and $R_{d}$. Because $C_{0}$ was raised to $3.0 \times 10^{-3} \mathrm{~m}^{-1}$, global mean liquid water path from $\mathrm{C}_{0}$ simulation is significantly decreased, by $7.2 \mathrm{~g} \mathrm{~m}^{-2}$ compared to $\mathrm{AG}$ simulation for $\mathrm{PD}$ condition (Table II). The anthropogenic aerosol indirect effect from $\mathrm{C}_{0}$ experiment $\left(-1.7 \mathrm{~W} \mathrm{~m}^{-2}\right)$ is remarkably larger than AG (1.4 $\mathrm{W} \mathrm{m} \mathrm{m}^{-2}$ ). Because $R_{d}$ was reduced from $16 \mu \mathrm{m}$ to $8 \mu \mathrm{m}$, column droplet number from $R_{d}$ simulation is significantly increased, by $0.61 \times 10^{10} \mathrm{~m}^{-2}$ as compared to $\mathrm{AD}$ under PI condition. Furthermore, global mean shortwave cloud forcing from $\mathrm{R}_{\mathrm{d}}$ simulation is increased by $-2.1 \mathrm{~W} \mathrm{~m}^{-2}$ (Table II). This difference is remarkably larger than anthropogenic aerosol indirect effect using AG parameterization $\left(1.4 \mathrm{~W} \mathrm{~m}^{-}\right.$ ${ }^{2}$ ). Roughly speaking, aerosol effects on convective clouds might be an important component for quantifying aerosol indirect effect.

\section{CONCLUSION AND Discussion}

The root of aerosol indirect effect is the droplet nucleation process. Several years ago, in most GCMs, droplet nucleation process was parameterized by empirical correlations between aerosols and droplets number concentrations. Previous studies showed that different empirical correlations could lead to a wide range of anthropogenic changes in the net radiative flux at the top of the atmosphere. In recent years, physically-based droplet nucleation parameterizations have been widely used in GCMs [9]. It seems that anthropogenic aerosol indirect effect is not sensitive to two different physically-based droplet nucleation parameterizations. However, anthropogenic aerosol indirect effect is quite sensitive to the sub-grid vertical velocities, which are used to drive droplet nucleation parameterization. 
Simulations in this paper show that annual global mean shortwave cloud forcing is sensitive to many tunable parameters in deep convective cloud scheme which should be relevant to aerosols. This indicates that aerosol impact on convective clouds might be an important component for quantifying aerosol indirect effect. Although it is very difficulty for GCMs to explicitly parameterize aerosol effects on convective clouds, recent developments show that this some GCMs start to address this issue [13, 14].

\section{REFERENCES}

[1] S. J. Ghan, and S. E. Schwartz, "Aerosol properties and processes - A path from field and laboratory measurements to global climate models," B Am Meteorol Soc, vol. 88(7), pp. 1059-1069, 2007.

[2] T. Storelvmo, U. Lohmann, and R. Bennartz, "What governs the spread in shortwave forcings in the transient IPCC AR4 models," Geophys Res Lett, vol. 36, 2009.

[3] A. Gettelman, H. Morrison, and S. J. Ghan, "A new two-moment bulk stratiform cloud microphysics scheme in the community atmosphere model," version 3 (CAM3). Part II: Single-colunm and global results, J Climate, vol. 21(15), pp. 3660-3679. (2008.

[4] U. Lohmann, P. Stier, C. Hoose, S. Ferrachat, S. Kloster, E. Roeckner, and J. Zhang, "Cloud microphysics and aerosol indirect effect in the global climate model ECHAM5-HAM," Atmos Chem Phys, vol. 7(13), pp. 3425-3446. (2007.

[5] H. Morrison, and A. Gettelman, "A new two-moment bulk stratiform cloud microphysics scheme in the community atmosphere model," version 3 (CAM3). Part I: Description and numerical tests, J Climate, vol. 21(15), pp. 3642-3659. (2008.

[6] X. J. Shi, B. Wang, X.H. Liu, M.H. Wang, L.J. Li, and L. Dong, "Aerosol Indirect effect on Warm Clouds in the Grid-Point Atmospheric Model of IAP LASG (GAMIL)," ATMOSPHERIC AND OCEANIC SCIENCE LETTERS, vol. 3(4) , pp. 237-241. (2010.

[7] H. Abdul-Razzak, and S. J. Ghan "A parameterization of aerosol activation 2. Multiple aerosol types," J Geophys Res-Atmos, 105(D5) , pp. 6837-6844, 2000.

[8] Nenes, and Seinfeld, "Parameterization of cloud droplet formation in global climate models," J. Geophys. Res, 108, 2003, doi:10.1029/2002JD1002 1911.

[9] S. J. Ghan, H. Abdul-Razzak, A. Nenes, Y. Ming, X. Liu, M. Ovchinnikov, B. Shipway, N. Meskhidze, J. Xu, and X. Shi, "Droplet Nucleation: Physically-Based Parameterizations and Comparative Evaluation," Journal of Advances in Modeling Earth Systems, 3(M10001), pp. 33, 2011.

[10] J. C. Golaz, M. Salzmann, L. J. Donner, L. W. Horowitz, Y. Ming, and M. Zhao, "Sensitivity of the aerosol indirect effect to sub-grid variability in the cloud parameterization of the GFDL Atmosphere General Circulation Model AM3," J.Climate, 2010.

[11] T. Storelvmo, J. E. Kristjansson, U. Lohmann, T. Iversen, A. Kirkevag, and O. Seland, "Modeling of the Wegener-BergeronFindeisen process-implications for aerosol indirect effect," Environ Res Lett, vol. 3(4), 2008.

[12] S. J. Lord, W. C. Chao, and A. Arakawa, "Interaction of a Cumulus Cloud Ensemble with the Large-Scale Environment. Part IV: The Discrete Model," J Atmos Sci, vol. 39(1) , pp. 104-113, 1982.

[13] X. Song, and G. J. Zhang, "Microphysics parameterization for convective clouds in a global climate model: Description and singlecolumn model tests," J. Geophys. Res., vol. 116(D2), D02201, 2011.

[14] M. Wang, S. Ghan, M. Ovchinnikov, X. Liu, R. Easter, E. Kassianov, Y. Qian, and H. Morrison, "Aerosol indirect effect in a multi-scale aerosol-climate model PNNL-MMF," Atmos. Chem. Phys. Discuss., vol. 11(1), pp. 3399-3459, 2011. 